\title{
Editorial
}

\section{Claudia Casapulla}

Professor, Department of Structure for Engineering and Architecture, University of Naples Federico II, via Forno Vecchio, Napoli, Italy

\section{Matthew Gilbert}

Professor, Department of Civil and Structural Engineering, University of Sheffield, UK
In recent decades, significant efforts have been made to improve our understanding of masonry gravity structures, employing a combination of advanced numerical analysis models, innovative non-destructive inspection technologies, and smart intervention solutions for restoration and retrofit. However, the structural assessment of both historical and modern masonry constructions, ranging from small adobe houses to monumental buildings and civil infrastructure, remains challenging, something that can only be addressed through new developments in many areas. The degree of complexity is added to by the strongly nonlinear mechanical behaviour of masonry, characterised by anisotropy, softening, damage, unilateral behaviour after cracking, and large variability in the types of materials used worldwide.

This two-part themed issue of Engineering and Computational Mechanics focuses on recent developments in the analysis models applied to masonry gravity structures. The first part was published in the June 2021 issue of the journal (Gilbert and Casapulla, 2021), while the second part presented here includes three papers, describing numerical approaches based on detailed (mesoscale) and simplified (macroscale) analysis models for both unreinforced and reinforced masonry structures.

Adopting a mesoscale modelling, the first paper, by Kao et al. (2021), proposes a computational method that frames the rigid-block equilibrium (RBE) problem as an optimisation problem to compute possible internal equilibrated stress states in masonry structures. Although this kind of limit analysisbased approach has already been widely adopted in the literature, the main contribution of this paper lies in modelling the normal contact forces via a penalty formulation, involving friction constraints at unilateral contacts. This formulation enlarges the space of admissible stress fields by allowing for tensile forces in potentially unstable regions. Feasible and infeasible solutions are considered for various benchmark problems (ranging from a pair of stacked blocks to a hemispherical dome). Thus, non-stable solutions can be explored, and interfaces subject to tensile forces can be identified. The approach builds on a method first introduced by Whiting et al. (2009), also adopted by Mousavian and Casapulla (2020) for interlocking block assemblages.
The second paper, by Celano et al. (2021), investigates the inplane behaviour of both unreinforced and fibre-reinforced cementitious material (FRCM) strengthened masonry walls under two testing conditions: diagonal-compression (Marcari et al., 2017), and shear-compression. Numerical results obtained using a bi-dimensional non-linear finite element (FE) macroscale model are compared for both wall configurations, considering local stress distributions. These highlight differences in terms of both distribution of stresses and global behaviour. Interesting observations on the values of the masonry shear strength derived from the two set-ups in the absence of compression are also made. In the future mesoscale models (e.g. those developed by De Proft et al. (2011) and by Milani and Lourenço (2011)) will be applied to the problem.

The final paper, by Pantò et al. (2021), introduces a novel discrete interface model endowed with rotating non-linear links, able to simulate the non-linear pure torsion behaviour and the torsion-shear-flexure interaction at cohesive-frictional contact interfaces in assemblages of masonry blocks, assumed to be rigid. The mechanical properties of the links are calibrated to simulate the global elastic stiffness of the masonry and the ultimate capacity of the contact interface. The orientation of the rotating links is updated during the incremental static analysis according to the current position of the twisting centre of the interface. Following the proposal of Casapulla and Maione (2018), the tendency for the pure torsion capacity to be overestimated (an issue highlighted by Tran-Cao (2009)) is removed. The model is validated against both experimental and numerical benchmarks from the literature (out-of-plane response of two stacked blocks and of a dry-jointed masonry wall constrained at one edge). The paper also presents results obtained from an implementation of the proposed model in discrete macro-element method (DMEM) software (Pantò et al., 2009), by applying an iterative Newton-Raphson algorithm to obtain equilibrium at the global structural level (mesoscale model).

Parts one and two of this themed issue contain papers describing a wide range of recent advancements in the numerical modelling of masonry gravity structures. We hope that the papers will stimulate interest in the topic among both researchers and practitioners, in turn leading to the development of novel numerical techniques and to exciting new applications. 


\section{REFERENCES}

Casapulla C and Maione A (2018) Modelling the dry-contact interface of rigid blocks under torsion and combined loadings: concavity vs. convexity formulation. International Journal of Non-Linear Mechanics 99: 86-96, https://doi.org/10.1016/j. ijnonlinmec.2017.11.002.

Celano T, Ceroni F and Lignola GP (2021) Behaviour of masonry walls strengthened with fibre-reinforced cementitious materials. Proceedings of the Institution of Civil Engineers - Engineering and Computational Mechanics 174(4): 193-214, https://doi.org/10.1680/ jencm.21.00009.

De Proft K, Heyens K and Sluys B (2011) Mesoscopic modelling of masonry failure. Proceedings of the Institution of Civil Engineers Engineering and Computational Mechanics 164(1): 41-46, https:// doi.org/10.1680/eacm.9.00013.

Kao GTC, lannuzzo A, Coros S, Van Mele T and Block P. (2021) Understanding the rigid-block equilibrium method by way of mathematical programming. Proceedings of the Institution of Civil Engineers - Engineering and Computational Mechanics 174(4): 178-192, https://doi.org/10.1680/jencm.20.00036.

Marcari G, Basili M and Vestroni F (2017) Experimental investigation of tuff masonry panels reinforced with surface bonded basalt textile-reinforced mortar. Composites Part B: Engineering 108: 131-142, https://doi.org/10.1016/j.compositesb.2016.09.094.
Milani G and Lourenço PB (2011) FE homogenised limit analysis model for masonry structures. Proceedings of the Institution of Civil Engineers - Engineering and Computational Mechanics 164(2): 65-78, https://doi.org/10.1680/eacm.2011.164.2.65.

Mousavian E and Casapulla C (2020) Quantifiable feasibility check of masonry assemblages composed of interlocking blocks. Advances in Engineering Software 149, 102898: 1-16, https://doi.org/10.1016/ j.advengsoft.2020.102898.

Pantò B, Cannizzaro F, Caliò I and Lourenço PB (2017) Numerical and experimental validation of a $3 \mathrm{D}$ macro-model for the in-plane and out-of-plane behavior of unreinforced masonry walls. International Journal of Architectural Heritage 11(7): 946-964, https://doi.org/ 10.1080/15583058.2017.1325539.

Pantò B, Casapulla C and Caliò I (2021) Discrete rotating links model for the non-linear torsion-shear behaviour of masonry joints. Proceedings of the Institution of Civil Engineers - Engineering and Computational Mechanics 174(4): 215-235, https://doi.org/10.1680/ jencm.21.00010.

Tran-Cao T (2009) Collapse Analysis of Block Structures in Frictional Contact. PhD thesis, The University of New South Wales, Sydney, Australia.

Whiting E, Ochsendorf J and Durand F (2009) Procedural modeling of structurally-sound masonry buildings. ACM Transactions on Graphics 28(5): 1-9. 